\title{
Limits on the potential accuracy of earthquake risk evaluations using the L'Aquila (Italy) earthquake as an example
}

\author{
John Douglas ${ }^{\star}$, Daniel Monfort Climent, Caterina Negulescu, Agathe Roullé, Olivier Sedan
}

BRGM - Bureau de Recherches Géologiques et Minières, Orléans, France

\author{
Article history \\ Received August 7, 2014; accepted January 13, 2015. \\ Subject classification: \\ Ground motion, Seismic risk, Statistical analysis, Algorithms and implementation, General or miscellaneous.
}

\section{ABSTRACT}

This article is concerned with attempting to 'predict' (hindcast) the damage caused by the L'Aquila 2009 earthquake $\left(M_{w} 6.3\right)$ and, more generally, with the question of how close predicted damage can ever be to observations. Damage is hindcast using a well-established empiricalbased approach based on vulnerability indices and macroseismic intensities, adjusted for local site effects. Using information that was available before the earthquake and assuming the same event characteristics as the L'Aquila mainshock, the overall damage is reasonably well predicted but there are considerable differences in the damage pattern. To understand the reasons for these differences, information that was only available after the event were include within the calculation. Despite some improvement in the predicted damage, in particularly by the modification of the vulnerability indices and the parameter influencing the width of the damage distribution, these hindcasts do not match all the details of the observations. This is because of local effects: both in terms of the ground shaking, which is only detectable by the installation of a much denser strong-motion network and a detailed microzonation, and in terms of the building vulnerability, which cannot be modeled using a statistical approach but would require detailed analytical modeling for which calibration data are likely to be lacking. Future studies should concentrate on adjusting the generic components of the approach to make them more applicable to their location of interest. To increase the number of observations available to make these adjustments, we encourage the collection of damage states (and not just habitability classes) following earthquakes and also the installation of dense strongmotion networks in built-up areas.

\section{Introduction}

Predicting the impact of future earthquakes is a key step of earthquake risk management. Generally the potential impact in terms of building and infrastructure damage, number of casualties and homeless people and the direct economic loss are predicted for various earthquake scenarios (e.g. a repeat of a historical event or the rupture of a nearby fault). The procedures followed to make these predictions have become increasingly so- phisticated but this invariably increases the need for detailed quantitative inputs. Consequently there remains a place for simpler, observationally-based methods to assess the impacts of potential earthquakes. One such procedure is the Level 1 approach developed within the RISK-UE project supported by the European Commission's Fifth Framework Programme [Mouroux and Le Brun 2006]. An extended version of this procedure has been used to develop many earthquake scenarios as part of public-service actions for the French Ministry of the Environment [Sedan et al. 2008]. Comparisons of the accuracy of damage predicted by this approach to observed damage in recent French earthquakes has been encouraging (e.g. Lourdes, 2006, $\mathrm{M}_{\mathrm{L}}$ 5; Sedan et al. [2013]) but these comparisons have been limited to small earthquakes $\left(\mathrm{M}_{\mathrm{w}}<5\right)$ because of France's moderate seismicity.

The aim of this article is to extend these comparisons to a highly-damaging earthquake. The recent L'Aquila (Italy) earthquake ( $\mathrm{M}_{\mathrm{w}} 6.3$ Global CMT) that occurred on April 6, 2009, has been chosen for this comparison: firstly, because it is similar to the type that could occur in mainland France, i.e. a shallow moderate earthquake occurring close to a city center composed of a mixture of pre-code, mainly masonry, dwellings and modern reinforced concrete (RC) structures, and, secondly, because of the wealth of available ground-truth data. As will be shown below, there are significant differences between the observed damage and that predicted by the standard Level 1 procedure for this earthquake. Consequently the main focus of this article is an analysis of the reasons for this difficulty in 'predicting' (hindcasting) and a discussion on the limits of earthquake risk evaluation. The overall objective of this study is to understand the critical aspects of the standard Level 1 procedure when it is applied in an operational context for risk assessments of a large geo- 
graphical zone where information is limited. More sophisticated procedures could be followed for small areas or where extensive field studies have been conducted but these approaches are rarely possible for public-service projects of a large zone.

Several damage hindcasts of the L'Aquila earthquake have been published. Karakostas et al. [2012] and Kontoes et al. [2012] have made them using a hybrid approach based on Italian and Greek fragility curves. Erdik et al. [2011] compare several rapid loss estimation procedures (PAGER, QLARM and ELER) using the L'Aquila earthquake as an example. Using the ELER method they also estimated the damage to buildings using four different ground-motion models. Sabetta [2011] also provides the loss estimates made by the Italian Civil Protection for this earthquake using the SIGE software. From the viewpoint of justifying the nonevacuation of L'Aquila during the seismic crisis, Zechar et al. [2014] and van Stiphout et al. [2010] estimated the damage using the QLARM software, which is based on EMS98 vulnerability classes. They used a generic vulnerability model for L'Aquila, with $30 \%$ of buildings in EMS98 class A (the most vulnerable), $30 \%$ in class B, $30 \%$ in class $\mathrm{C}$ and $10 \%$ in class $\mathrm{D}$ (the least vulnerable). This generic distribution will be discussed later in the present article.

Considering hindcasts for other recent moderate earthquakes in Europe, Rivas-Medina et al. [2014] compare predicted and observed damage for the Lorca 2011 earthquake $\left(\mathrm{M}_{\mathrm{w}} 5.1\right.$ Global CMT $)$ in Spain. They used several ground-motion prediction equations (GMPEs) and standard RISK-UE Level 2 capacity curves from Lagomarsino and Giovinazzi [2006]. They note difficulties in comparing habitability diagnostics for buildings and scenario damage states. Another difficulty encountered is the simulation of specific building types, specifically: old masonry and RC-frame buildings. Masonry structures are predicted to be more damaged than they were in reality. The situation is reversed for the RC buildings: they experienced greater damage than the predictions would suggest. However, looking at the whole of Lorca, these differences roughly compensate and the global simulated damage is quite close to reality but they show large local discrepancies.

The Liege 1983 earthquake $\left(M_{L} 4.9\right)$ in Belgium is studied by Garcia-Moreno and Camelbeeck [2013]. Their goal is quite different to the present article: they estimate ground-motion maps in terms of peak ground and pseudo-spectral acceleration (PGA and PSA, respectively) that best explain the observed damage. The inversion was made using two sets of fragility and vulnerability curves for masonry buildings: those of HAZUS and those of Lang and Bachmann [2004]. Kauf- mann and Schwarz [2008] compared several EMS98 vulnerability assessments with observed damage from the Albstadt (Germany) 1978 earthquake ( $\mathrm{M}_{\mathrm{L}}$ 5.7).

In the next section the risk evaluation procedure followed here is outlined. Section 3 presents various attempts to hindcast the observed damage (i.e. predict the damage using only information that was available before the earthquake assuming the size and location of the event is known). Since significant differences between the observed and 'predicted' damage are identified, Section 4 analyses the reasons for this difference. The article ends with some discussion of the results and recommendations for future risk evaluations.

\section{Level 1 risk evaluation procedure}

The risk evaluation procedure used here consists of various steps, which are briefly outlined in this section. It is assumed that the magnitude and location (hypocenter and fault position) of the earthquake are precisely known (and equal to those assessed after the L'Aquila event), along with any other earthquake characteristics (e.g. normal-faulting mechanism) required to evaluate the GMPEs considered. This assumption is made because it is the basis of deterministic scenariobased risk evaluations.

The first step of the procedure is to estimate the PGA or peak ground velocity (PGV) using a GMPE assuming a uniform site condition, generally a standard rock class (here Eurocode 8 class A), for every grid location where the damage is to be estimated. In this study, because of the level of detail available on the observed building damage, two different areas are considered: a large area of central Italy centered on L'Aquila, where macroseismic intensities are available (but detailed damage observations are not); and a much smaller area covering only the city of L'Aquila, where details of the observed damage are known in addition to a detailed microzonation of local site effects. At the scale of the L'Aquila municipality the grid size was $15 \mathrm{~m}$.

Next the impact of local site effects on PGA and PGV due to variations in the near-surface lithology and, possibly, topography (not considered here) are modeled by applying site amplification factors using a site classification map (ideally based on a microzonation of the area). The maps of PGA and PGV taking account of the local site effects are then converted to macroseismic intensity in terms of the European Macroseismic Scale (EMS98) [Council of Europe 1998] using a groundmotion-intensity conversion equation (GMICE). Intensity estimates in terms of EMS98 summarize the effects of the earthquake at that location on a twelve-point integer scale. In this study this is the final step of the procedure for the risk evaluation of the wide region of 
central Italy.

For the detailed damage assessment for the city of L'Aquila three additional steps are necessary, which were developed within RISK-UE [Lagomarsino and Giovinazzi 2006]. Firstly, the fragility to earthquake shaking of the elements at risk (for this study, dwellings) are characterized by vulnerability indices $\left(V_{i}\right)$, which range from zero (no vulnerability to earthquake shaking) to one (building is highly vulnerable to shaking). A value of $V_{i}$ is assigned to each building type (defined in terms of its age, material and technique of construction and, potentially, other characteristics). Next, based on the $V_{i}$ and the assessed intensity at each location, the mean damage degree $\left(\mu_{D}\right.$, between zero and five) is estimated based on a vulnerability function. Finally, the distribution of damage at each location is assessed based on $\mu_{D}$ and a value $t$, which governs the spread of the distribution, by using a beta distribution. The final outcome is the distribution in terms of the six levels defined in EMS98: D0 (undamaged), D1 (slight damage), D2 (moderate damage), D3 (heavy damage), D4 (partial collapse) and D5 (total collapse) for each location that is separately considered.

This procedure is programmed in the in-house BRGM software Armagedom, which was used for the computations presented here. Details on the procedure and the software are provided by Sedan et al. [2013].

\subsection{GMPEs for L'Aquila}

Two of the GMPEs proposed by the project SHARE for the construction of a harmonized seismic hazard map for Europe [Delavaud et al. 2012] are used here for the estimation of damage. These are: Akkar and Bommer [2010], which was derived by regression analysis on about 500 strong-motion records from Europe and the Middle East, and Cauzzi and Faccioli [2008], which was based on analysis of about 1200 accelerograms mainly from Japan but with some data from California, Europe and Iran. These two GMPEs were given the highest weight in the logic tree by Delavaud et al. [2012].

\subsection{Local site effects in L'Aquila and wider region}

Di Capua et al. [2011] present a national EC8 site class map based on surface geology, which is used for the analysis of the wide region. To assess the damage scenarios, each site class is translated into amplification factors for PGA and PGV using the EC8 spectra.

The national EC 8 site class map being established at a scale of $1: 100,000$, it is not fully adapted to cityscale damage assessments. To improve our analysis of local site effects and their implications for damage estimation when focusing on L'Aquila, we used the ad- vanced seismic microzonations performed at a scale better than 1:10,000 for L'Aquila, Onna, Paganica, Barisciano, San Pio delle Camere and Castelnuovo [Gruppo di Lavoro MS-AQ 2010]. For those microzonations, 1D or $2 \mathrm{D}$ numerical simulations were performed following the approach described by the Gruppo di Lavoro MS [2008]. Two amplifications factors $\mathrm{F}_{\mathrm{A}}$ and $\mathrm{F}_{\mathrm{V}}$ are calculated respectively from the maximum acceleration spectral response and the maximum velocity spectral response.

\subsection{Vulnerability assessment for current buildings}

In this study only current dwellings have been considered using the building census data freely provided by ISTAT [2001]. These census data provide information about the total number of buildings; the age and materials of construction, either RC or masonry, are given but this information is not cross-referenced. Information is provided at a district or locality level (one municipality is divided into $\mathrm{n}$ localities). The newest census data (from 2011) do not provide all this information [ISTAT 2014]. The vulnerability of the current dwellings are characterized for the procedure followed here using the following two steps.

\begin{tabular}{cccccc} 
& & \multicolumn{4}{c}{ Vulnerability class (EMS98) in \% } \\
\cline { 3 - 6 } & Age of building & A & B & C & D \\
\hline I & Before 1919 & 64.0 & 26.8 & 8.4 & 0.8 \\
II & $1919-1945$ & 41.3 & 36.5 & 18.7 & 3.5 \\
III & $1946-1961$ & 16.8 & 34.2 & 32.8 & 16.2 \\
IV & $1962-1971$ & 4.8 & 14.8 & 33.4 & 47.0 \\
V & $1972-1981$ & 24.2 & 11.4 & 27.5 & 36.9 \\
VI & After 1982 & 0.4 & 4.2 & 9.0 & 86.4 \\
\hline
\end{tabular}

Table 1. Distribution matrix of the vulnerability classes EMS98 with the reference to the age of building, taken from Zuccaro et al. [2012].

\begin{tabular}{cccccc} 
& $\begin{array}{c}\text { From Bernardini } \\
\text { et al. [2007] }\end{array}$ & & \multicolumn{3}{c}{ Modified here } \\
\cline { 2 - 3 } $\begin{array}{c}\text { EMS98 } \\
\text { vulnerability } \\
\text { classes }\end{array}$ & $V_{i}$ & & $V_{i}$ & $t$ & Reference \\
\hline A & 0.880 & & 0.850 & 8 & Figure 9 \\
B & 0.720 & & 0.700 & 8 & Figure 10 \\
C & 0.560 & & 0.700 & 16 & Figure 10 \\
D & 0.400 & 0.525 & 10 & Figure 11 \\
\hline
\end{tabular}

Table 2. EMS98 vulnerability classes and RISK-UE vulnerability indexes $V_{i}$ used for the "blind" scenario [Bernardini et al. 2007] ( $t=6$ was used for all classes) and the modified $V_{i}$ and $t$ parameters according to observations of Rossetto et al. [2009], Liel and Linch [2009] and Tertulliani et al. [2010]. 
Firstly, Zuccaro et al. [2012] proposes a preliminary method to classify Italian current building into EMS98 vulnerability classes as a function of age of construction (Table 1). This method is adapted to the 2001 census information provided by ISTAT. Local variations in building type are not taken into account at this level of study. This is discussed later on in this article.

Secondly, EMS98 vulnerability classes are converted into RISK-UE vulnerability indexes following the approach of Bernardini et al. [2007]. Therefore, for the hindcast the vulnerability indices that have been used are the ones presented in Table 2.

\subsection{Observed macroseismic intensities in central Italy}

The observed intensities using the Mercalli-Cancani-Sieberg (MCS) scale reported by Galli et al. [2009] are available in the DMBI database [Stucchi et al. 2007, Locati et al. 2011]. So as to facilitate comparisons with the predicted intensities (made at all grid points within the area), these observations are interpolated using kriging with a trend [e.g. Douglas 2007] taking account of the fault location. It should be noted that strictly speaking intensities are integers and hence they cannot be processed in this way. The assumption that intensities can be manipulated like continuous variables is, however, commonly made because it enables analyses (in this case, interpolation) that would not be possible if intensities were considered only as integers. Nevertheless, the reader is cautioned against over-interpreting details of the interpolated intensities. These interpolated intensities (Figure 1) are used here as the basis of the comparisons for the wide region of central Italy. Following Musson et al. [2010], it is assumed here that intensities on the MCS and EMS98 scales are equivalent.

\subsection{Observed damage in L'Aquila}

Tertulliani et al. [2010] describe the exhaustive building-to-building survey performed in the center of L'Aquila to evaluate the damage and to compile an inventory of building types according to EMS98 guidelines [Council of Europe 1998]. Tertulliani et al. [2010] present these valuable results as maps of vulnerability classes and damage grades. These damage grades are the basis of the comparisons for the city of L'Aquila.

\section{Hindcasting the observations}

This section discusses several options for hindcasting the damage observations. The first method is called the "standard approach" or "blind scenario". In this approach the only measured data used are the epicentral coordinates and the moment magnitude. Next the median ground motions (PGA or PGV) are estimated using a GMPE taking into account a national EC8 site classification map, the estimation of the macroseismic intensity using a published GMICE and, finally, the damage assessment using, in the present work, the RISK-UE procedure. As noted above two GMPEs adapted to European context have been used and for the Akkar and Bommer

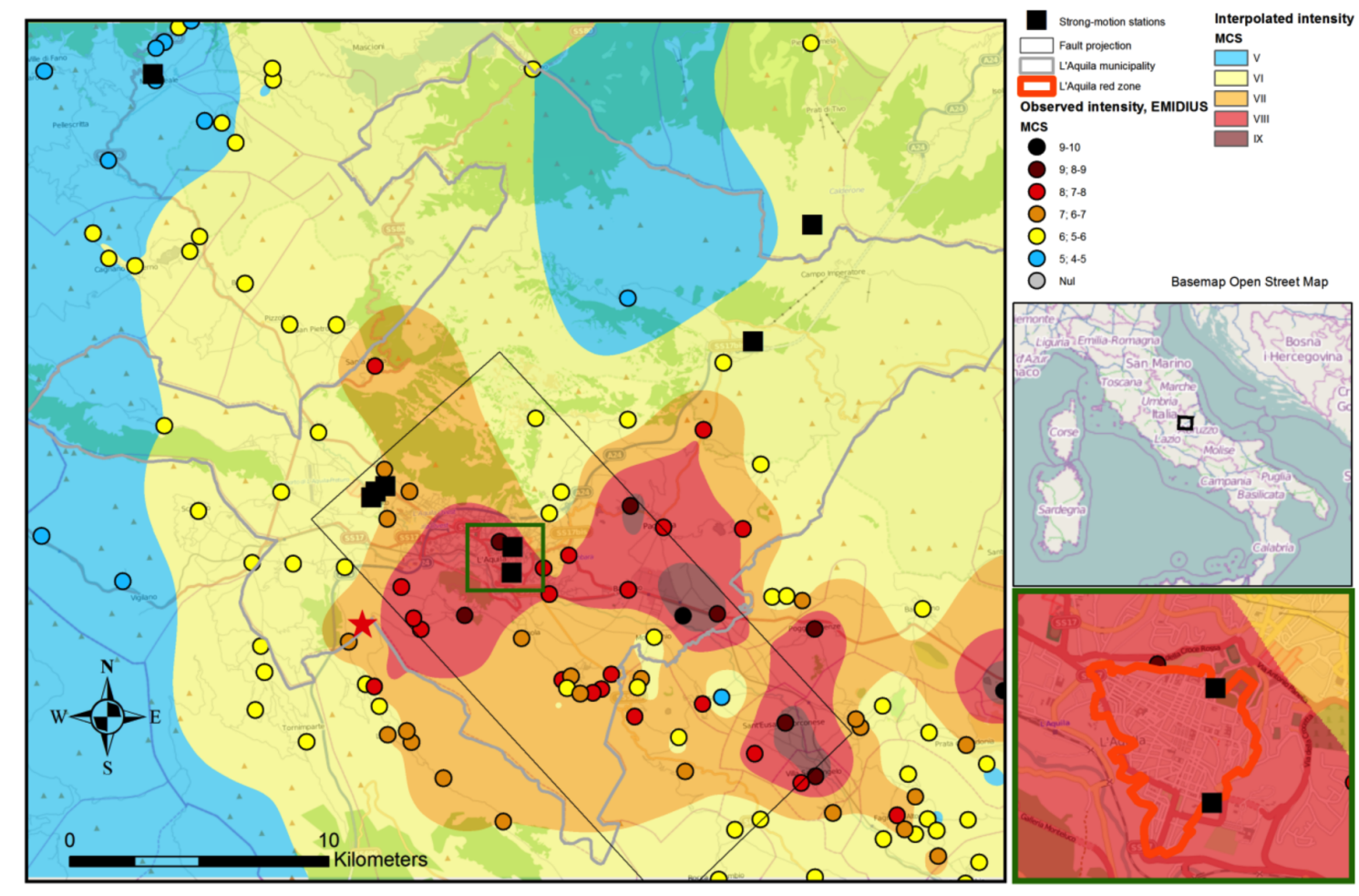

Figure 1. Interpolated macroseismic intensities using the intensities of Galli et al. [2009] reported in the DMBI-EMIDIUS database [Locati et al. 2011]. Isoseismals indicate the interpolated intensities whereas the observations are shown as colored circles. 
[2010] model the fault location available on the INGV (the Italian Istituto Nazionale di Geofisica e Vulcanologia) ShakeMap website has been taken into account.

The comparisons of macroseismic intensites for the wide region are shown in Figure 2. It can be seen that there are considerable differences between the predictions and observations for this standard approach. The following sections seek to improve the match by various techniques. The idea here is to quantify the impact of uncertainties in each of these steps on the final result by using available observations for a given event to avoid (bypass) a given step. For example, using the observed PGAs (or PGVs) from a dense strong-motion network in the epicentral zone rather than a GMPE will quantify the possible reduction if this step was perfectly performed and using the observed macroseismic in-
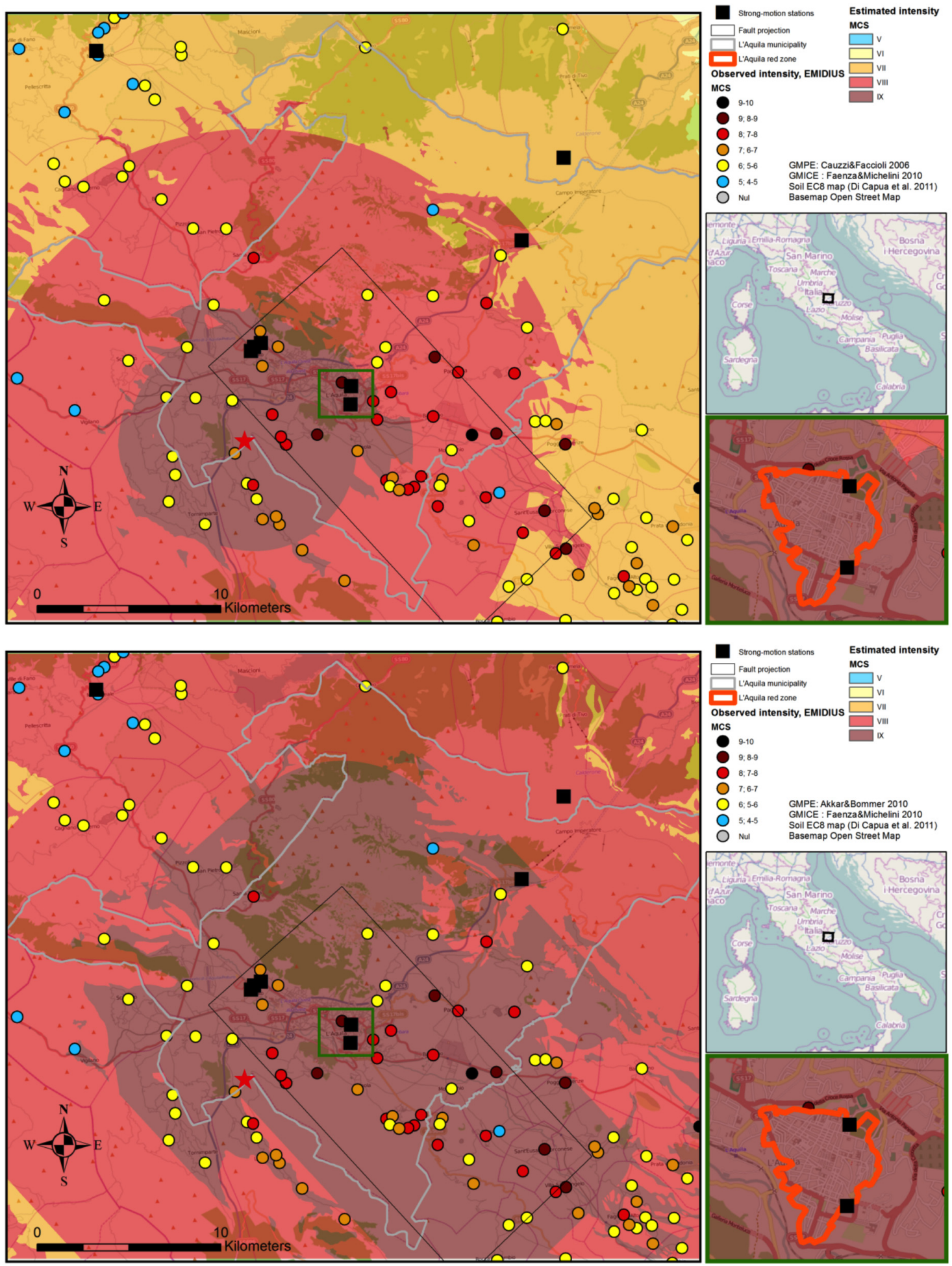

Figure 2. Comparison between hindcast macroseismic intensities (MCS) using Cauzzi and Faccioli [2008] (top) and Akkar and Bommer [2010] (bottom) and those observed (MCS, DMBI-EMIDIUS). 
tensity map will eliminate the uncertainties from the first three steps.

\subsection{Improving estimated ground motions}

The first way in which the predictions could be made more similar to the observations is to improve the ground-motion estimates. This was done here by making use of the strong-motion records for this earthquake and the kriging with a trend technique [e.g. Douglas 2007] (Figure 3). The procedure followed was that the observed PGAs and PGVs at each of the strong-motion stations that recorded this earthquake were adjusted to the Eurocode 8 (EC8) A class (rock) by using the Italian EC8 site class map of Di Capua et al. [2011] and the site amplifications of the EC8 design spectra for the different classes (spectral acceleration at $0.5 \mathrm{~s}$ was used as a proxy for PGV following Bommer and Alarcon [2006]), these were then kriged and the EC8 amplifications were subsequently applied to the resulting ground-motion map.

Given the low density of stations in the L'Aquila area (only five stations in the city) the estimated ground-motion field shows little spatial variation. This means that the use of this map to avoid the uncertainties of the first three steps is likely to not significantly reduce the mismatch with observations, except for possibly removing an overall bias because the average ground motions in the city were higher (or lower) than would be expected based on a GMPE.

Figure 4 compares the observed and estimated in- tensities at locations near L'Aquila using the various approaches. In many locations intensity is overestimated. In many villages close to the epicenter low intensities (VI or less) were observed, which could be related to fault directivity towards the south and spatial variability of the ground motions. GMPEs generally assume isotropic attenuation in all directions and the instrumental network was not dense enough to capture the heterogeneities. The historical center of L'Aquila is one of the points where observed and estimated intensities (VIII-IX) are similar.

In Italy, the software ShakeMap has been operational at the Istituto Nazionale di Geofisica e Vulcanologia since 2006 [Michelini et al. 2008, Faenza and Michelini 2010]. According to Faenza and Michelini [2010], this software uses the GMICE of Wald et al. [1999]. The ShakeMap for the L'Aquila earthquake is available on Shakemap INGV archives (INGV [2009], http: / / shakemap.rm.ingv.it/shake/2206496920/intensity.html). The predicted intensities for this event vary between VII and VIII in the L'Aquila municipality. This estimated intensity map has been used as one of the attempts to better match the observations.

\subsection{Adjusting the GMICE}

After the PGA and PGV are estimated they are converted to macroseismic intensity through a GMICE. Because of their wide use in Italy and elsewhere, two models have been considered here [Wald et al. 1999, Faenza and Michelini 2010]. Neither of these use obser-
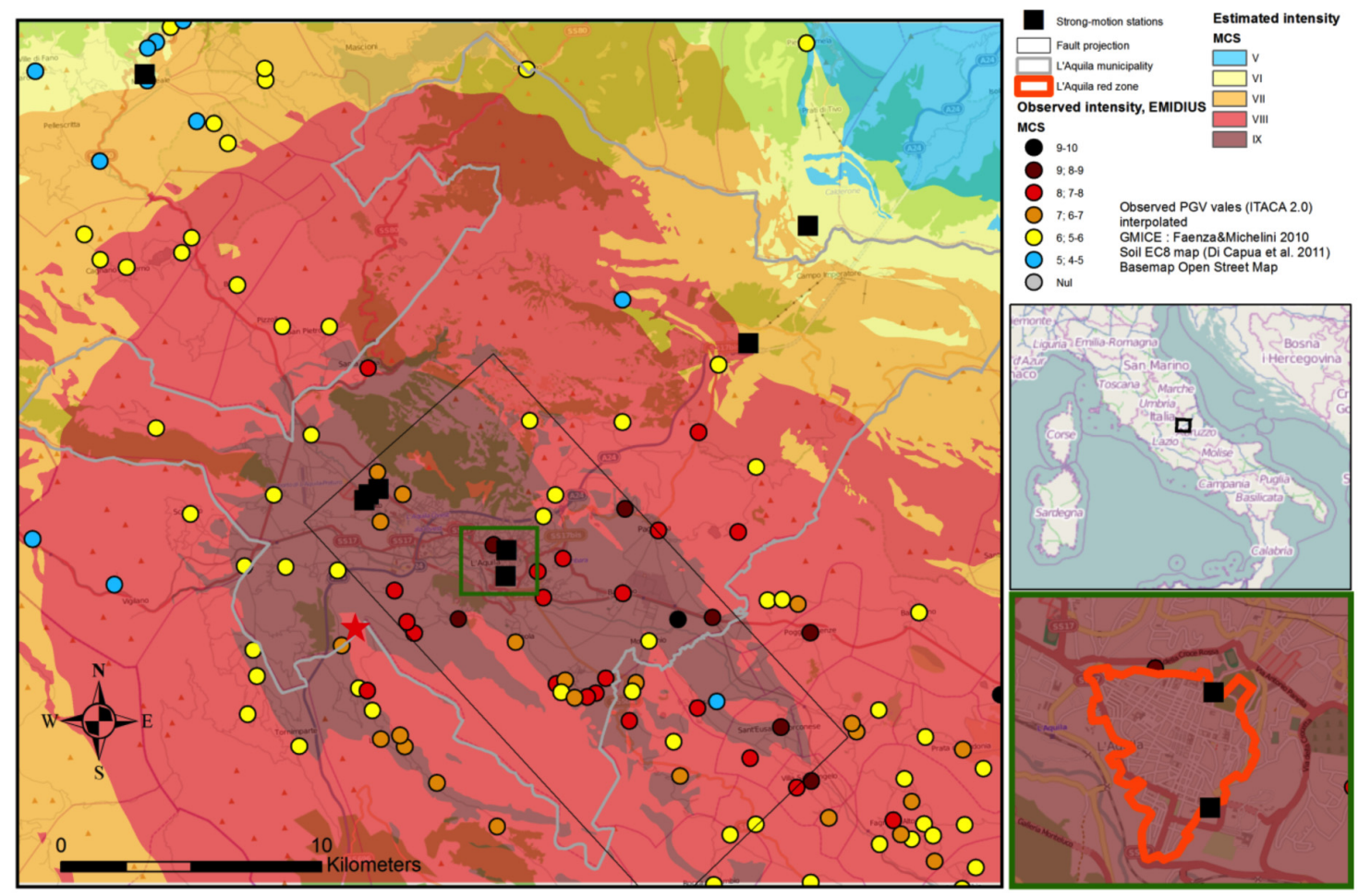

Figure 3. Comparison between hindcast macroseismic intensities using kriging of measured PGV and those observed in L'Aquila (EMIDIUS). 

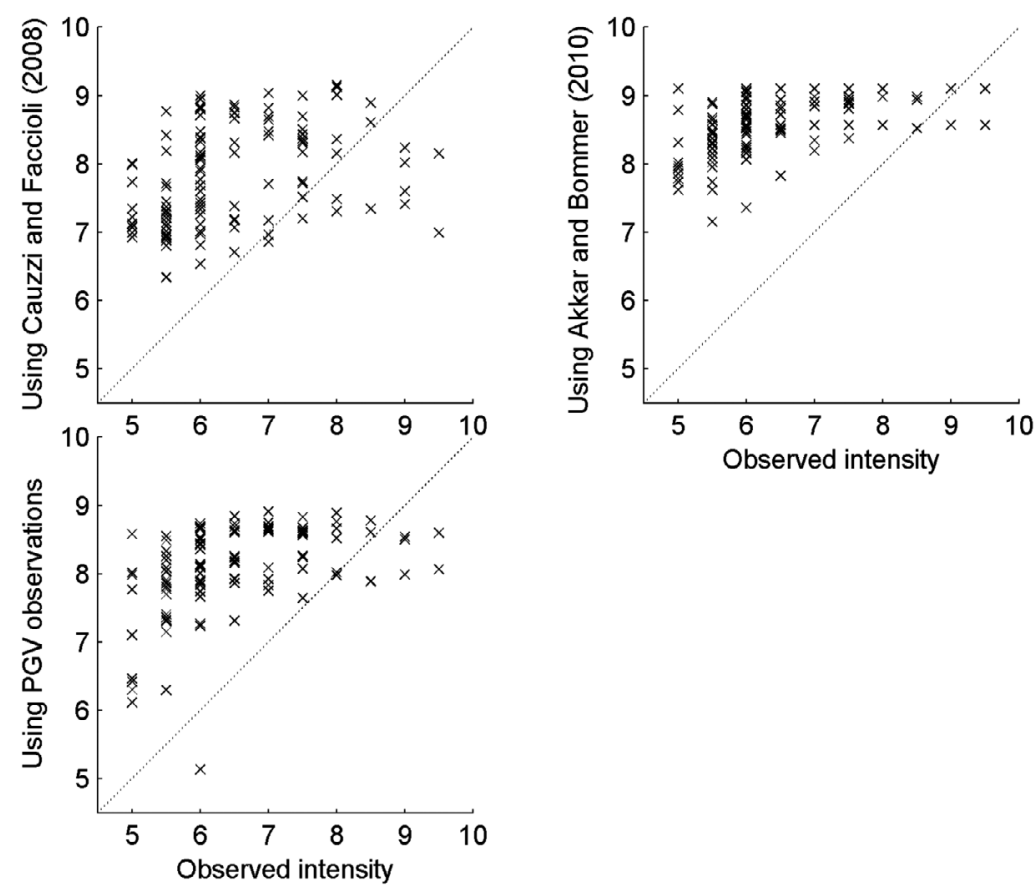

Figure 4. Comparison between observed intensities and those predicted by the three different approaches shown in Figure 2 and Figure 3

vations from the L'Aquila earthquake and, hence, it is useful to check their applicability to these data by comparing observed and predicted intensities based on observed PGAs and PGVs (Figure 5). From this comparison it can be seen that for PGA the model of Faenza and Michelini [2010] roughly matches the observations whereas for PGV the model of Wald et al. [1999] is better. However, the ranges of measured PGAs and PGVs for the same intensity level are very large, e.g. the ranges for intensity $\mathrm{V}$ span over an order of magnitude (factor of ten). Consequently, this transformation introduces much uncertainty into the procedure. This could be avoided by predicting EMS98 intensity directly but this would require reliable intensity prediction equations to be available that take into account local site effects.

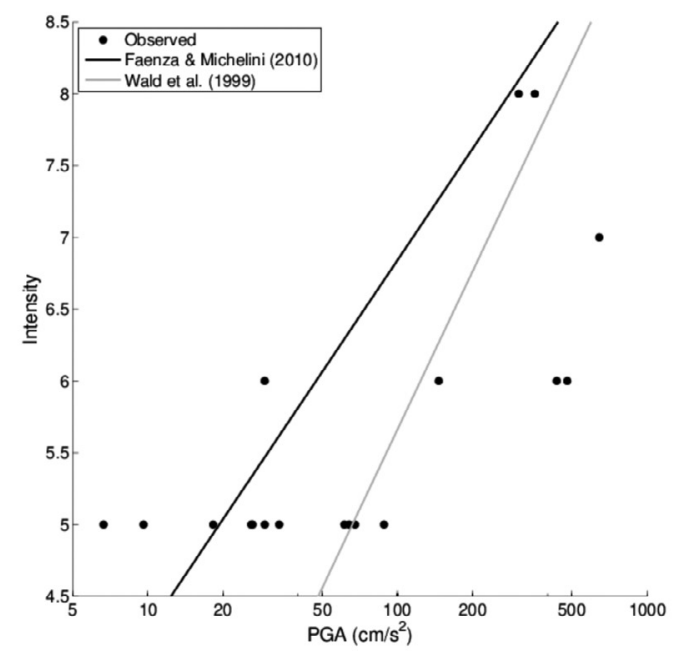

\subsection{Impact of site effects on intensities}

Within the risk evaluation reported here, site amplification is accounted for by its influence on PGA and PGV and, subsequently, through the GMICE on macroseismic intensity. To understand the influence that variations in site conditions could have on the assessed intensities, the increment in intensity ( I) for both PGA and PGV are computed using two different GMICEs (those of Faeza and Michellini [2010] and Wald et al. [1999]) for the range of site amplifications specified in the microzonation of Gruppo di Lavoro MS-AQ [2010] (Figure 6). For the site amplifications for the EC 8 site classes (A, B, C and D), EC 8 design spectra [CEN 2005] for these classes are used; as noted above, for PGV the site amplification for a spectral acceleration of $0.5 \mathrm{~s}$ is used as a

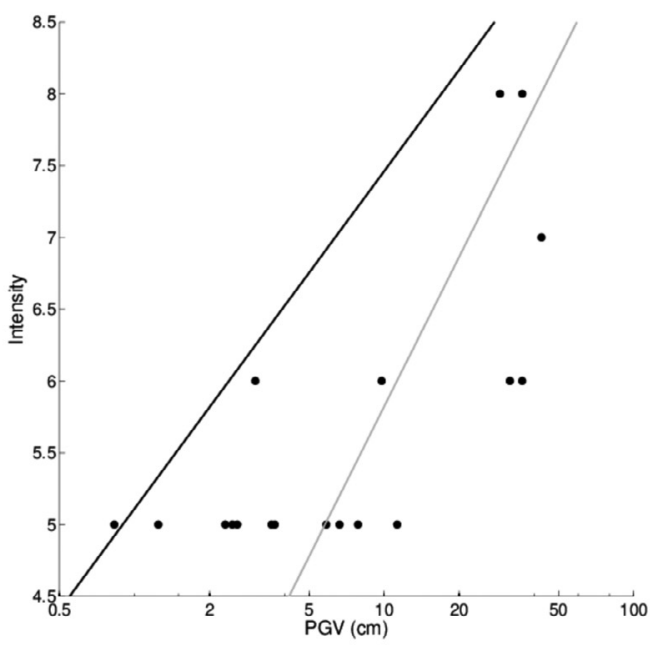

Figure 5. Comparison of intensities observed in the L'Aquila earthquake and those predicted by the GMICEs of Faenza and Michelini [2010] and Wald et al. [1999]. 

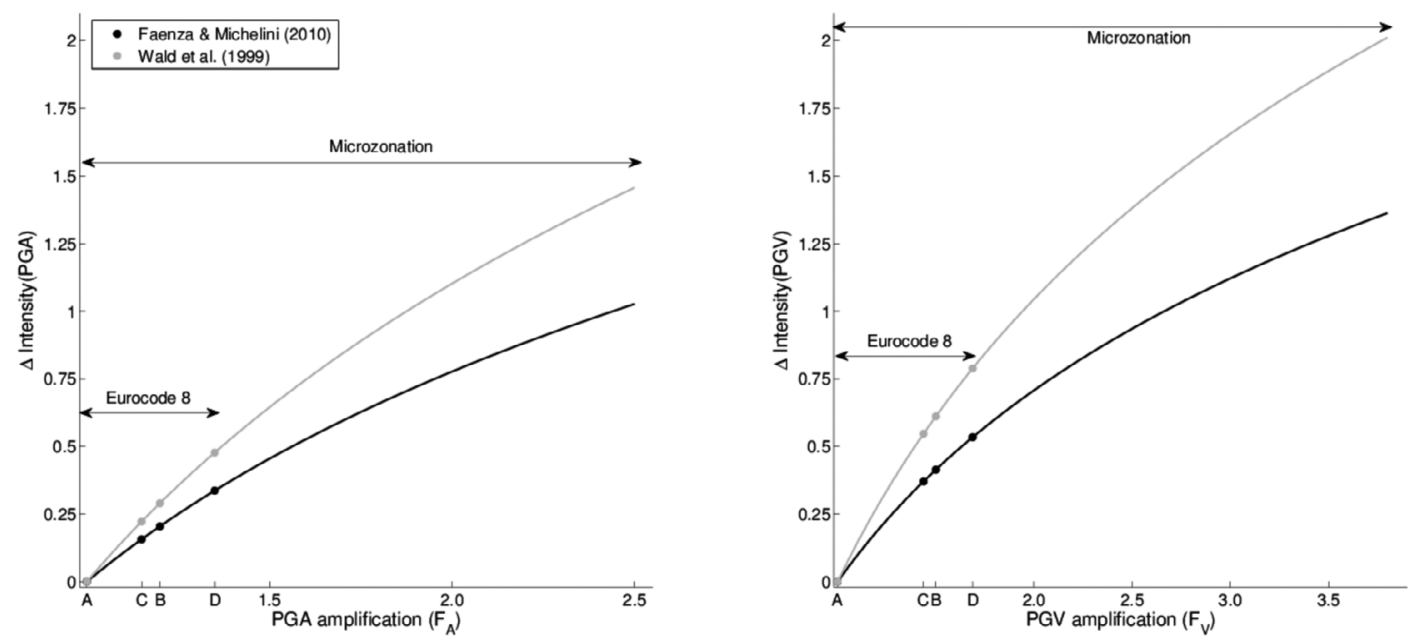

Figure 6. Effect of PGA and SA(0.5s) (proxy for PGV) site amplifications on macroseismic intensities for two GMICEs and the site factors predicted by Eurocode 8 and the microzonation of L'Aquila.

proxy following Bommer and Alarcon [2006]. Since the site amplifications specified in the microzonation [Gruppo di Lavoro MS-AQ 2010] are with respect to the plateau of the acceleration $\left(\mathrm{F}_{\mathrm{A}}\right)$ and velocity $\left(\mathrm{F}_{\mathrm{V}}\right)$ spectra of the sites it is not possible to clearly relate this to amplification of PGA and PGV but this assumption has been made here. This could overemphasize the importance of site amplification on macroseismic intensities.

Studying Figure 6 suggests that amplifications implied by EC 8 lead to a limited effect on the intensities (less than half a unit with respect to rock intensities) but in the case of site amplifications evidenced in mi- crozonations for L'Aquila $\Delta \mathrm{I}$ can reach one unit or more. Such variations are noticeable on the observed macroseismic intensities and hence are contributing to the mismatch between predictions (made without access to the microzonations) and observations.

\subsection{Results}

The results of these attempts are summarized in Figure 7 and Figure 8 for the historical center of L'Aquila. They are roughly arranged with respect to how much information that was only available after the earthquake is used. Table 3 summarizes the character-

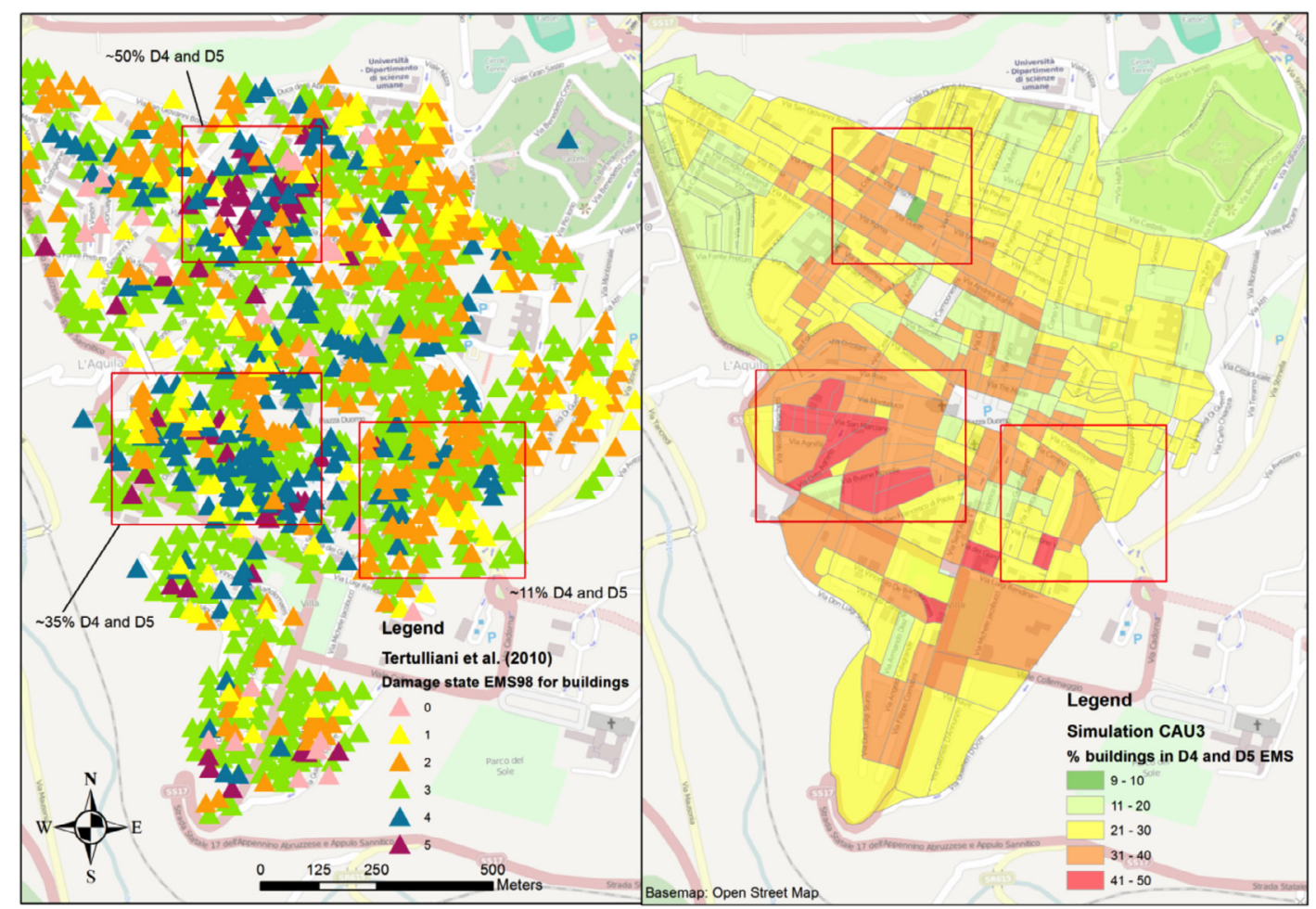

Figure 7. Comparison between hindcast damage states (right: by neighborhood) using the most complete approach (CAU3) and those observed (left: by building) in the center of L'Aquila [Tertulliani et al. 2010]. 


\begin{tabular}{|c|c|c|}
\hline ID & Ground-motion input & Building vulnerabilities \\
\hline SKM1 & INGV shakemap & Zuccaro et al. [2012] \\
\hline OINT1 & $\begin{array}{l}\text { Observed intensities interpolated } \\
\text { [Galli et al. 2009] }\end{array}$ & \\
\hline OPGV1 & $\begin{array}{l}\text { Measured bedrock PGV from kriging } \\
\text { GMICE: Faenza and Michelini [2010] } \\
\text { Site effects: national EC8 map }\end{array}$ & \\
\hline AK1 & $\begin{array}{l}\text { GMPE: Akkar and Bommer [2010] } \\
\text { GMICE: Faenza and Michelini [2010] } \\
\text { Site effects: national EC8 map }\end{array}$ & \\
\hline CAU1 & $\begin{array}{l}\text { GMPE: Cauzzi and Faccioli [2006] } \\
\text { GMICE: Faenza and Michelini [2010] } \\
\text { Site effects: national EC } 8 \text { map }\end{array}$ & \\
\hline SKM2 & INGV shakemap & $\begin{array}{l}\text { Based on Zuccaro et al. [2012] and ISTAT2001 with new } \\
\text { vulnerability index and } t \text { value based on observations. }\end{array}$ \\
\hline OINT2 & $\begin{array}{l}\text { Observed intensities interpolated } \\
\text { [Galli et al. 2009] }\end{array}$ & \\
\hline OPGV2 & $\begin{array}{l}\text { Measured bedrock PGV from kriging } \\
\text { GMICE: Faenza and Michelini [2010] } \\
\text { Site effects: national EC } 8 \text { map }\end{array}$ & \\
\hline $\mathrm{AK} 2$ & $\begin{array}{l}\text { GMPE: Akkar and Bommer [2010] } \\
\text { GMICE: Faenza and Michelini [2010] } \\
\text { Site effects: national EC } 8 \text { map }\end{array}$ & \\
\hline CAU2 & $\begin{array}{l}\text { GMPE: Cauzzi and Faccioli [2006] } \\
\text { GMICE: Faenza and Michelini [2010] } \\
\text { Site effects: national EC } 8 \text { map }\end{array}$ & \\
\hline CAU3 & $\begin{array}{l}\text { GMPE: Cauzzi and Faccioli [2006] } \\
\text { GMICE: Faenza and Michelini [2010] } \\
\text { Site effects: Microzonation (only in historical center of L'Aquila) }\end{array}$ & \\
\hline CAU4 & Same as CAU3 & $\begin{array}{l}\text { Simulation only done for L'Aquila historical center. } \\
\text { EMS98 vulnerability classes observed by Tertulliani et al. }\end{array}$ \\
\hline IX CNT & $\begin{array}{l}\text { Constant intensity IX is assumed } \\
\text { for the entire historical center of L'Aquila. }\end{array}$ & $\begin{array}{l}\text { [2010] distributed homogeneously in the red zone. } \\
\text { Vulnerability index and } t \text { value as discussed above. }\end{array}$ \\
\hline
\end{tabular}

Table 3. Synthesis of the simulations considered in the present work.

istics of each simulation and Table 4 presents the main results in terms of damage buildings for comparison to the observations. It can be seen that, despite using much additional information, there remain large differences between the hindcasts and the observations. The reasons for this are discussed in the following section.

\section{Why the observed damage cannot be 'predicted'}

The best results should be obtained using the interpolated macroseismic intensity map (since we are basically starting with the answer) but this is not observed. The possible reasons for this are the following:

- Differences between the distribution of damage and modeled distributions for different $t$ and $V_{i}$;

- Inconsistency between macroseismic intensities and reported damage (reported damage higher than in- tensities suggest);

- Bi-modal damage distribution coming from two populations of buildings (low and high vulnerabilities); and

- Tails of the distributions: what is the lowest ground motion/intensity where damage is observed?

The first three of these possibilities are investigated in this section. The fourth is not considered here since it would require more detailed information on the observed ground motions than provided by the handful of strong-motion stations in L'Aquila.

\subsection{Observed damage distributions}

Following the L'Aquila earthquake, many research teams undertook field surveys of building damage in different areas. Liel and Lynch [2009] estimated dam- 


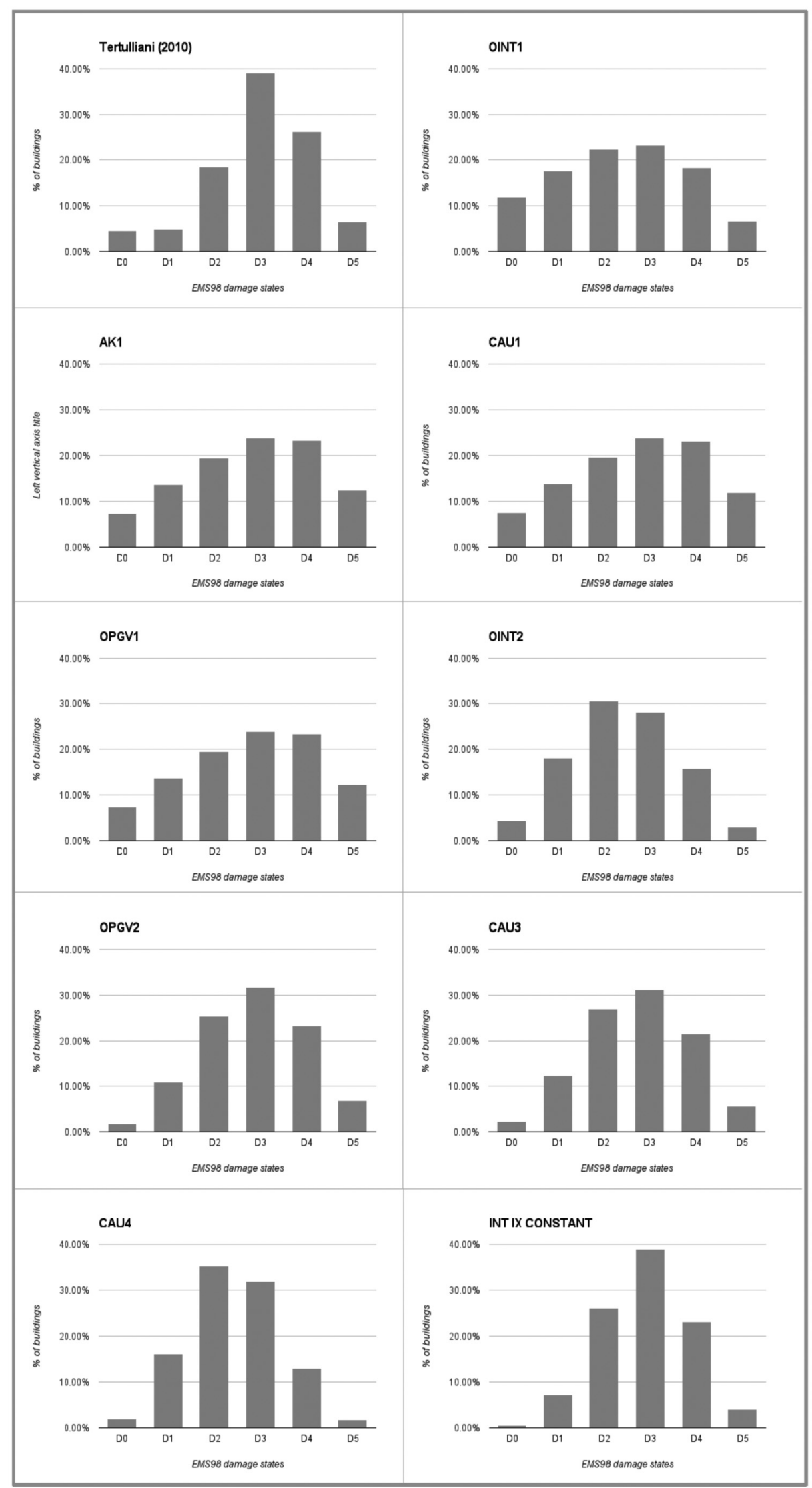

Figure 8. Distribution of damage states in L'Aquila observed by Tertulliani et al. [2010] and simulations.

age states for RC residential buildings in L'Aquila. Figure 9 presents the distributions of damage states assuming two different distributions of building height: for Case 1 the height distribution of the L'Aquila RC buildings is the same as the height distribution in the original field database and for Case 2 the height distri- 


\begin{tabular}{|c|c|c|c|c|c|c|c|c|}
\hline \multirow{3}{*}{ ID } & \multirow{3}{*}{$\begin{array}{l}\text { Intensity } \\
\text { L'Aquila his- } \\
\text { torical center }\end{array}$} & \multicolumn{3}{|c|}{ Number of D4 and D5 buildings } & \multicolumn{4}{|c|}{ Number of inhabitable buildings (class E) } \\
\hline & & \multicolumn{2}{|c|}{ Simulated } & \multirow{2}{*}{$\begin{array}{c}\begin{array}{c}\text { Observed } \\
{[\text { Tertulliani et }} \\
\text { al. 2010] }\end{array} \\
\text { Center }^{\star \star ~}\end{array}$} & \multicolumn{2}{|c|}{ Simulated $^{\star}$} & \multicolumn{2}{|c|}{ Observed (AeDES) } \\
\hline & & Municipality & Center & & Municipality & Center & Municipality & $\begin{array}{c}\text { Center } \\
\text { (red zone) }\end{array}$ \\
\hline SKM1 & VII-VIII & 744 & 152 & & 2694 & 546 & & \\
\hline OINT1 & VIII & 1315 & 376 & & 3493 & 834 & & \\
\hline OPGV1 & VIII-IX & 3522 & 538 & & 7110 & 981 & & \\
\hline AK1 & IX & 4633 & 543 & & 8336 & 989 & & \\
\hline CAU1 & VIII-IX & 3265 & 533 & & 6782 & 982 & & \\
\hline SKM2 & VII-VIII & 403 & 86 & & 2159 & 513 & & \\
\hline OINT2 & VIII & 931 & 284 & 504 & 3307 & 864 & 6616 & 748 \\
\hline OPGV2 & VIII-IX & 3014 & 458 & & 8159 & 1047 & & \\
\hline AK2 & IX & 4386 & 596 & & 10112 & 1149 & & \\
\hline CAU2 & VIII-IX & 2756 & 445 & & 7651 & 1035 & & \\
\hline CAU3 & VIII-IX & 4285 & 410 & & 9546 & 1004 & & \\
\hline CAU4 & VIII-IX & - & 243 & & - & 971 & & \\
\hline IX CNT & IX & - & 452 & & - & 1207 & & \\
\hline
\end{tabular}

Table 4. Results of the different simulations for the L'Aquila municipality. $\left.{ }^{\star}\right)$ Transformation based on Table 6 (E=100\% of D4 and D5

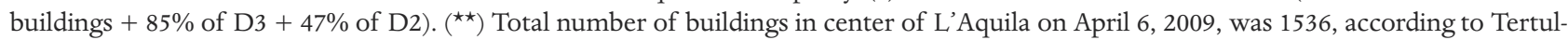
liani et al. [2010]. Total number of buildings considered in this scenario, based on ISTAT [2001], data is 1511. Total number of buildings in red zone (zona rossa) in the center of L'Aquila according to AeDES is 1238.

bution is updated based on available census data for L'Aquila. This comparison shows that, for the RC structures in Aquila, the vulnerability index that best fits the damage distribution observed by Liel and Lynch [2009] for the Case 1 is $V_{i}=0.6$ and for Case $2 V_{i}=0.5$ and a $t$ value, governing the damage distribution, of 8 . Hence, for RC structures in L'Aquila the initial value considered in the "blind" scenario (Table 2) seems to underestimate the vulnerability of this type of structure.

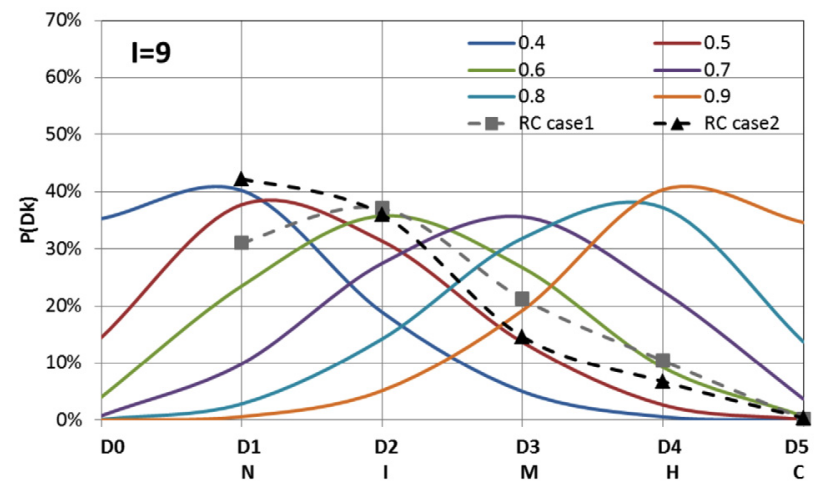

In their preliminary field report following the L'Aquila earthquake, Rossetto et al. [2009] report the building damage distribution in Onna. Figure 10 compares the RISK-UE damage distribution for macroseismic intensity IX-X and for $V_{i}$ between 0.7 and 0.9 to the observed damage distribution for Onna. In this case, $V_{i}=$ 0.88 chosen in the "blind" scenario seems to be a good assumption. A $t$ value of 8 is assumed. Considering the observed data in Onna, all the masonry buildings would

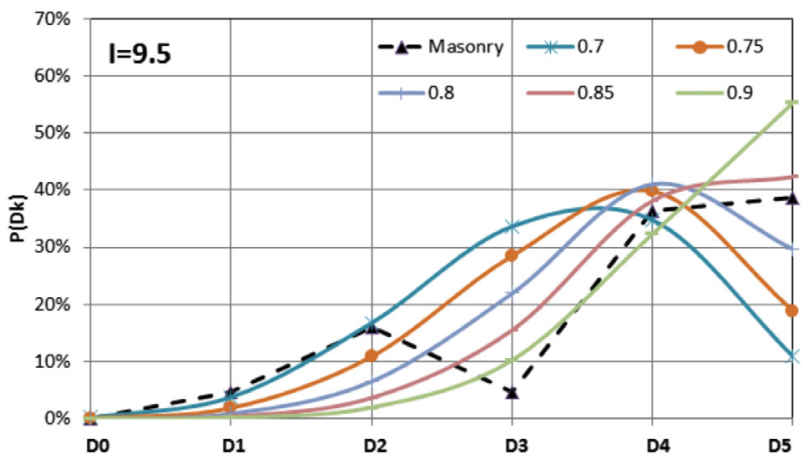

Figure 9 (left). Damage distribution using the RISK-UE approach for macroseismic intensity IX and different vulnerability indexes $\left(V_{i}=0.4-\right.$ least vulnerable to $V_{i}=0.9$ - most vulnerable) and the discrete damage distributions [Liel and Lynch 2009] for two different assumptions on building heights: RC case 1 - height distribution based on field database and RC case 2 - height distribution updated with available census data for L'Aquila. Figure 10 (right). Damage continuous distribution using the RISK-UE approach for intensity IX-X and different vulnerability indexes and the discrete damage distribution of masonry buildings observed in Onna [Rossetto et al. 2009]. 


\begin{tabular}{|c|c|c|c|c|c|c|c|c|c|}
\hline & \multicolumn{7}{|c|}{ Onna by age } & \multicolumn{2}{|c|}{ By type } \\
\hline & $\begin{array}{c}\text { Before } \\
1919\end{array}$ & $\begin{array}{c}\text { Between } \\
1919 \\
\text { and } 1945\end{array}$ & $\begin{array}{c}\text { Between } \\
1946 \\
\text { and } 1961\end{array}$ & $\begin{array}{c}\text { Between } \\
1962 \\
\text { and } 1971\end{array}$ & $\begin{array}{c}\text { Between } \\
1972 \\
\text { and } 1981\end{array}$ & $\begin{array}{c}\text { Between } \\
1982 \\
\text { and } 1991\end{array}$ & $\begin{array}{l}\text { After } \\
1991\end{array}$ & Masonry & $\mathrm{RC}$ \\
\hline $\begin{array}{l}\text { Number } \\
\text { of buildings }\end{array}$ & 33 & 8 & 4 & 6 & 17 & 31 & 16 & 93 & 22 \\
\hline $\begin{array}{l}\text { EMS98 } \\
\text { classes }\end{array}$ & A & B & $\mathrm{C}$ & $\mathrm{D}$ & & & & & \\
\hline $\begin{array}{l}\text { Number } \\
\text { of buildings }\end{array}$ & 48 & 18 & 16 & 51 & & & & & \\
\hline
\end{tabular}

\begin{tabular}{|c|c|c|c|c|c|c|c|c|c|}
\hline & \multicolumn{7}{|c|}{ L'Aquila red zone by age } & \multicolumn{2}{|c|}{ By type } \\
\hline & $\begin{array}{c}\text { Before } \\
1919\end{array}$ & $\begin{array}{c}\text { Between } \\
1919 \\
\text { and } 1945\end{array}$ & $\begin{array}{c}\text { Between } \\
1946 \\
\text { and } 1961\end{array}$ & $\begin{array}{c}\text { Between } \\
1962 \\
\text { and } 1971\end{array}$ & $\begin{array}{c}\text { Between } \\
1972 \\
\text { and } 1981\end{array}$ & $\begin{array}{c}\text { Between } \\
1982 \\
\text { and } 1991\end{array}$ & $\begin{array}{l}\text { After } \\
1991\end{array}$ & Masonry & $\mathrm{RC}$ \\
\hline $\begin{array}{l}\text { Number } \\
\text { of buildings }\end{array}$ & 934 & 219 & 239 & 115 & 21 & 3 & 1 & 1135 & 304 \\
\hline $\begin{array}{l}\text { EMS98 } \\
\text { classes }\end{array}$ & A & B & $\mathrm{C}$ & $\mathrm{D}$ & & & & & \\
\hline $\begin{array}{l}\text { Number } \\
\text { of buildings }\end{array}$ & 740 & 432 & 242 & 119 & & & & & \\
\hline
\end{tabular}

\begin{tabular}{|c|c|c|c|c|c|c|c|c|c|}
\hline & \multicolumn{7}{|c|}{ L'Aquila municipality by age } & \multicolumn{2}{|c|}{ By type } \\
\hline & $\begin{array}{c}\text { Before } \\
1919\end{array}$ & $\begin{array}{c}\text { Between } \\
1919 \\
\text { and } 1945\end{array}$ & $\begin{array}{c}\text { Between } \\
1946 \\
\text { and } 1961\end{array}$ & $\begin{array}{c}\text { Between } \\
1962 \\
\text { and } 1971\end{array}$ & $\begin{array}{c}\text { Between } \\
1972 \\
\text { and } 1981\end{array}$ & $\begin{array}{c}\text { Between } \\
1982 \\
\text { and } 1991\end{array}$ & $\begin{array}{c}\text { After } \\
1991\end{array}$ & Masonry & $\mathrm{RC}$ \\
\hline $\begin{array}{l}\text { Number } \\
\text { of buildings }\end{array}$ & 3563 & 1628 & 1626 & 1756 & 2445 & 2099 & 971 & 8614 & 4113 \\
\hline $\begin{array}{l}\text { EMS98 } \\
\text { classes }\end{array}$ & A & B & $\mathrm{C}$ & $\mathrm{D}$ & & & & & \\
\hline $\begin{array}{l}\text { Number } \\
\text { of buildings }\end{array}$ & 5129 & 2777 & 2672 & 4728 & & & & & \\
\hline
\end{tabular}

Table 5. ISTAT [2001] data for Onna, L'Aquila red zone and L'Aquila municipality and the distribution in EMS98 vulnerability classes using the approach of Zuccaro et al. [2012].

be classed in vulnerability class A according to EMS98. Following the global vulnerability assessment by Zuccaro et al. [2012] and ISTAT [2001] data for Onna, the building stock in Onna would be classified as shown in Table 5. Even if observations by Rossetto et al. [2009] do not include all buildings in Onna, it seems clear that the classification using Zuccaro et al. [2012] tends to underestimate the number of buildings in vulnerability class A. On the other hand the number of buildings in vulnerability class $\mathrm{D}$ is probably overestimated.

It seems appropriate to use in the same scenario different values of $t$ for the various vulnerability classes (e.g. for vulnerability class $\mathrm{A} t$ equal to 8 is the best choice while for the vulnerability classes $\mathrm{B}$ and $\mathrm{C} t$ equal to 16 appears better). In the "blind" scenario we used the same $t$ value for the all the vulnerability classes but when trying to improve the match to the observations different values of $t$ are used (as is allowed by the software we use). For vulnerability classes A, B and C, the observations from field reports show a uni-modal damage distribution that is consistent with the beta distribution proposed by the RISK-UE approach for each building type. This is not seen for the vulnerability class $\mathrm{D}$, which seems to present a bi-modal damage distribution coming from two populations of buildings (low and high vulnerabilities, Figure 10). It should be noted, however, that there are only eight buildings in class $\mathrm{D}$ reported by Tertulliani et al. [2010], which is too few to conclude on a bi-modal distribution.

In Figure 7 the damage distribution observed in the 
historical centre of L'Aquila is compared with the damage distribution obtained with these updated simulations. Damage state D3 was by far the most common observed in this area while the simulated damage largely underestimates the number of buildings in damage state D3 and the overall distribution is broader than the observations. When the vulnerability indexes and the $t$ parameter are modified (Table 2), the results fit much better to the observations of Tertulliani et al. [2010]. In this case D3 is clearly the most common estimated damage state, which is related to the value of $t$ used here.

The EMS98 vulnerability distribution from the field survey of the historical center of L'Aquila [Tertulliani et al. 2010] can be compared with the vulnerability distribution obtained using the approach of Zuccaro et al. [2012] coupled with the ISTAT [2001] data. As can be seen (Figure 12) for Tertulliani et al. [2010] the most common vulnerability class is B while using the census data the most common is class A. Two further simulations considering Tertulliani et al. [2010]'s vulnerability distribution (CAU4 and IX CNT), only in the L'Aquila historical perimeter were conducted. When the whole zone is assumed to correspond to intensity IX (IX CNT), damage estimated by simulations and the Tertulliani et al. [2010] damage observations are quite close. The closest match is found when using observed building classes, adapted vulnerability functions and $t$ values (as discussed previously) and intensity fixed to IX, which is the observed highest intensity in this area. Tertulliani et al. [2010] discuss that the EMS98 intensity in the center of L'Aquila varies between VIII and IX because the damage distributed with respect to the vulnerability classes matches quite well the distributions expected for both intensities.

Looking at scenario CAU3 in detail (Figure 7), the most damaged area in L'Aquila is to the south-west of the historical center, where local site effects are large. This generally agrees with the descriptions of Tertulliani et al. [2010] and Contreras et al. [2014]. This area is identified by the microzonation by a soil effect and consequently the damage scenario takes this situation into account. On the other hand, the north-west part of the historical center was heavily damaged but the simulations do not predict this. Tertulliani et al. [2010] note that the buildings in this area are built on rubble/landfill but the available microzonation considers this area as bedrock [Gruppo di lavoro MS-AQ 2010].

\subsection{Damage states and habitability}

Following the earthquake the Italian Civil Protection, through their AeDES form [Chianello et al. 2009, Dipartimento della Protezione Civile 2009], classified dwellings with respect to their habitability, i.e. whether
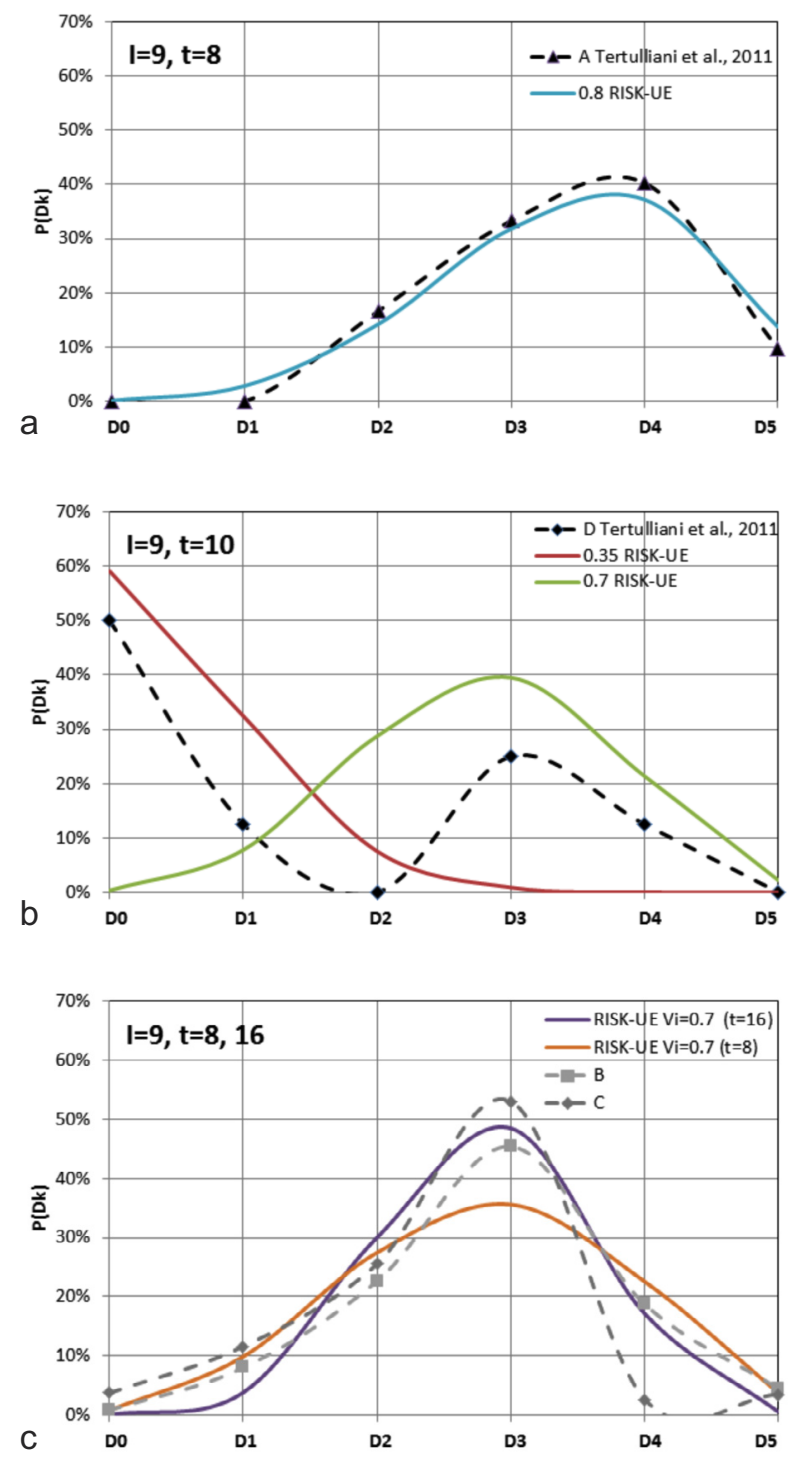

Figure 11. Calibration of the vulnerability indexes and of the " $t$ " parameter for EMS98 vulnerability classes (class A-a, class D- b and classes B and C -c) based on data from Tertulliani et al. [2010].

they are safe to live in. This report gives the number of buildings per habitability state aggregated by city district. To compare it with damage simulations, the question is: how to convert EMS98 damage states (predicted by the RISK-UE Level 1 procedure) into habitability states?

Karakostas et al. [2012] noted that no straightforward comparison can be made between structural (fragility curves) and usability (statistical) damage states. They assumed that: usability categories A and F correspond to structurally "green" buildings (DS0 and DS1); categories B, C and D to "yellow" (DS2 and DS3); and category E to "red" (DS4 and DS5), leading to a 44.1\% "green", 18.3\% "yellow" and 37.6\% "red" distribution.

Comune di L'Aquila [2014] (L'Aquila municipal council) has published a public GIS with the AeDES habitability diagnostic for each building, based on cadaster delimitation. Using this information for the L'Aquila historical center and the observed damage state from Ter- 


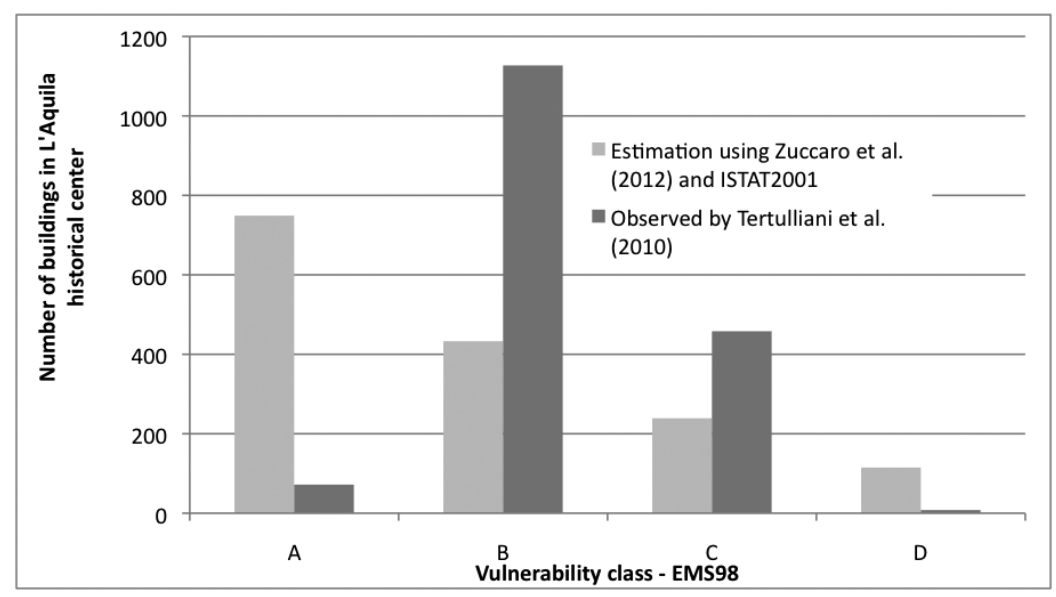

Figure 12. Distribution of vulnerability classes in L'Aquila using two approaches.

tulliani et al. [2010], the two data sources can be compared for 204 buildings. Table 6 presents the relation between EMS98 and AeDES states. It can be seen that EMS98 damage states D0 and D1 correspond mainly to habitability states A and B. On the other side D4 and D5 corresponds, unsurprisingly, to habitability state E. Following Tertulliani et al. [2010] damage state D3 was the most common in L'Aquila center and a large number of these buildings were classed in $\mathrm{E}$ by the AeDES procedure. Buildings in damage state D2 have been classed equally between $\mathrm{E}$ and $\mathrm{A}-\mathrm{B}$ habitability states. The values observed in Table 6 are used to predict the habitability of the current building stock (Table 4).

These results, although based on only a limited number of buildings in the center of L'Aquila, show the difficulty of using only habitability reports for this kind of work. This complexity has also been found by
Rivas-Medina et al. [2014] in Lorca. In any case, there does not exist a clear relation between qualitative damage states according to a macroseismic intensity scale and habitability states.

\section{Conclusions and recommendations}

One of the objectives of the present study was to see how closely a hindcast blind scenario would match the observed damage. The standard approach predicts the overall damage ratios in L'Aquila quite well. However, locally, great differences between observations and predicted damages are seen. These differences are due to: seismic source heterogeneities and directivity, lithological site effects including very local effects (e.g. landfill), individual building vulnerability variations, including specificities that cannot be taken into account using a statistical approach. Current statistically-based seismic risk

AeDES habitability states [Comune di L'Aquila 2014]

\begin{tabular}{ccccc}
\hline A & B & C & D & E \\
\hline & $\begin{array}{c}\text { Temporarily } \\
\text { inhabitable } \\
\text { building. }\end{array}$ & Building & $\begin{array}{c}\text { Temporarily } \\
\text { inhabitable } \\
\text { building. }\end{array}$ & \\
Habitable & pabitable & partially & Habitable & Inhabitable \\
building & inhabitable & after & building \\
& low/rapid & & significant & \\
& work & & work & \\
& & &
\end{tabular}

\begin{tabular}{|c|c|c|c|c|c|c|}
\hline & Do & 2 & 2 & - & - & - \\
\hline EMS98 & D1 & 5 & 11 & - & - & 1 \\
\hline $\begin{array}{c}\text { damage states } \\
\text { observed by }\end{array}$ & D2 & 6 & 14 & 1 & - & 19 \\
\hline $\begin{array}{c}\text { Tertulliani } \\
\text { et al. [2010] }\end{array}$ & D3 & 1 & 11 & 4 & - & 106 \\
\hline \multirow[t]{2}{*}{ in L'Aquila } & D4 & - & - & - & - & 16 \\
\hline & D5 & - & - & - & - & 5 \\
\hline
\end{tabular}

Table 6. Relation between EMS98 damage states observed by Tertulliani et al. [2010] and its AeDES habitability state [Comune di L'Aquila 2014] for 204 buildings. Note: There is a sixth habitability class 'F' meaning 'Inhabitable building caused by neighboring buildings/elements' but this is not present in the sample of buildings considered here. 
procedures cannot reproduce all these situations.

It appears that it is more important to predict correctly the ground-motion intensity than use the most appropriate vulnerability functions since an error of, say, one macroseismic intensity unit leads to a great difference in predicted damage. For the purposes of observational-based damage evaluations it would be useful to derive state-of-the-art intensity prediction equations that better account for earthquake source properties (e.g. faulting mechanism) and local site conditions in the style of recent GMPEs. This would avoid the introduction of large uncertainties when converting instrumental intensity measures (e.g. PGA and PGV) to macroseismic intensity through GMICEs.

Retro-analysis of earthquake damage is generally limited by a lack of strong-motion stations since it is not possible to ascertain the shaking that a neighbor experiences. This study confirms the conclusion of Crowley et al. [2008] who show that, without a dense strong-motion network, it is impossible to validate earthquake loss models because the uncertainty in the ground motion often overwhelms the other uncertainties. Low-cost strongmotion sensors (e.g. based on micro-electro-mechanical systems) could allow a significant increase in the density of strong-motion networks, especially in urban areas. Such instrumentation has great potential in improving vulnerability functions [Ioannou et al. 2015].

Concerning potential improvements to vulnerability functions, this study has highlighted the importance of using a $t$ value, controlling the width of the beta distribution, that is adapted to each building type. In addition, it has demonstrated that some recent RC buildings (at first glance of low vulnerability) can perform poorly in earthquake shaking, leading to underestimation of earthquake damage, whereas on the other hand some masonry structures (apparently of high vulnerability) can resist seismic shaking, leading to overestimating potential losses. A similar observation was made by Rivas-Medina et al. [2014] for the Lorca earthquake. This is an important observation since European towns are characterized by various proportions of RC and masonry buildings. The EMS-98 scale does allow for the possibility that RC buildings can be more vulnerable than masonry but this is not commonly appreciated in risk scenarios.

Lastly, as Rivas-Medina et al. [2014] observed in Lorca, this work has confronted the difficulties in comparing building habitability and damage states. After future earthquakes, a field investigation like that conducted by Tertulliani et al. [2010] would be useful for classifying buildings into EMS98 damage states to avoid the need for assumptions concerning equivalence between building habitability and damage levels. Such field trips would improve the observations necessary for the comparison of simulations and observations and to improve models of damage distributions in earthquakes.

\section{Data and sharing resources}

Census data and Italian city district delimitation is taken from ISTAT: http:/ / www.istat.it/it/archivio/ 104 317 (last accessed August 4, 2014).

ShakeMaps are taken from: http:/ / shakemap.rm. ingv.it/shake/2206496920/products.html (last accessed August 4, 2014).

L'Aquila earthquake observed intensities are taken from DMBI-EMIDIUS database: http: / / emidius.mi.ingv. it/DBMI11 / query_eq/20090406.htm (last accessed August 4, 2014).

Building habitability classifications in L'Aquila municipality are taken from: http:/ / laquila.geoportal.it/ websit $/$ default.aspx?Utente=laquila (last accessed August 4, 2014).

Microzonations data are taken from: http:/ / www. protezionecivile.gov.it/jcms/it/microzonazione_aqui lano.wp (last accessed August 5, 2014).

Building damage observations for the center of L'Aquila are taken from Tertulliani et al. [2010].

Open Street Map was used as the base map.

Giuseppe Di Capua (INGV) provided the GIS file of the Italian site classification.

Acknowledgements. This study was supported by an internal BRGM project (Multirisk). Developments of the risk evaluation procedure used here have been supported by various projects, including by the French Ministry of the Environment, the World Bank and the European Commission. We thank: Giuseppe Di Capua for providing the GIS file of the Italian site classification and Julien Duhauvelle for data compilation and GIS treatment. Lastly, we are grateful to two anonymous reviewers for their careful and constructive comments on an earlier version of this article.

\section{References}

Akkar, S., and J.J. Bommer (2010). Empirical Equations for the Prediction of PGA, PGV, and Spectral Accelerations in Europe, the Mediterranean Region, and the Middle East, Seismol. Res. Lett., 81 (2), 195206; doi:10.1785/gssrl.81.2.195.

Bernardini, A., S. Giovinazzi, S. Lagomarsino and S. Parodi (2007). Vulnerabilità e previsione di danno a scala territoriale secondo una metodologia macrosismica coerente con la scala EMS-98, In: Proceedings of the XII conference ANIDIS (Pisa, Italy, June 10-14), (in Italian).

Bommer, J.J., and J.E. Alarcon (2006). The prediction and use of peak ground velocity, J. Earthq. Eng., 10 (1), 1-31; doi:10.1080/13632460609350586.

Cauzzi, C., and E. Faccioli (2008). Broadband (0.05 to $20 \mathrm{~s})$ prediction of displacement response spectra 
based on worldwide digital records, J. Seismol., 12 (4), 453-475; doi:10.1007/s10950-008-9098-y.

Chianello, G.M., R. Raschi, M. Rebuffat and F. Papa (2009). Manuale per la compilazione della scheda di $1^{\circ}$ livello di rilevamento danno, pronto intervento e agibilità per edifici ordinari nell'emergenza post-sismica (AeDES), Dipartimento della Protezione Civile, (in Italian).

CEN, Comité Européen de Normalisation (2005). Eurocode 8, Design of structures for earthquake resistance - Part 1: General rules, seismic actions and rules for buildings. European Standard NF EN 1998-1.

Comune di L'Aquila (2014). Assessorato alla Ricostruzione e Pianificazione: Settore pianificazione e ripianificazione del territorio, S.I.T.; online GIS: http:/ / laquila.geoportal.it $/$ websit $/$ default.aspx?Utente $=$ la quila.

Contreras, D., T. Blaschke, S. Kienberger and P. Zeil (2014). Myths and realities about the recovery of L'Aquila after the earthquake, International Journal of Disaster Risk Reduction, 8, 125-142; doi:10.1016/ j.ijdrr.2014.02.001.

Council of Europe (1998). European macroseismic scale 1998 (EMS-98), G. Grünthal (ed.), vol. 15, Centre Européen du Géodynamique et de Séismologie, Luxembourg.

Crowley, H., P.J. Stafford and J.J. Bommer (2008). Can earthquake loss models be validated using field observations?, J. Earthq. Eng., 12 (7), 1078-1104; doi:10. $1080 / 13632460802212923$.

Delavaud, E., F. Cotton, S. Akkar, F. Scherbaum, L. Danciu, C. Beauval, S. Drouet, J. Douglas, R. Basili, M.A. Sandikkaya, M. Segou, E. Faccioli and N. Theodoulidis (2012). Toward a ground-motion logic tree for probabilistic seismic hazard assessment in Europe, J. Seismol., 16 (3), 451-473; doi:10.1007/s10 950-012-9281-z

Di Capua, G., S. Peppoloni, M. Amanti, C. Cipolloni, G. Conte, D. Avola, A. Del Buono, E. Borgomeo, C. Negri Arnoldi and S. Scrivieri (2011). Il Progetto SEE-GeoForm: uno strumento per la consultazione di dati geologici e di pericolosita sismica riferiti all'intero territorio nazionale, In: Proceedings of the XIV conference ANIDIS (Bari, Italy, September 1822), (in Italian).

Dipartimento della Protezione Civile (2009). Ordinanza 3753/2009. Eventi sismici provincia dell'Aquila, 6 Aprile 2009. DICOMAC. FUNZIONE 1- Tecnica di Valutazione e censimento danni, Rapporto attività di sopralluogo effettuate al: 15/06/2009, (in Italian).

Douglas, J. (2007). Inferred ground motions on Guadeloupe during the 2004 Les Saintes earthquake, B. Earthq. Eng., 5 (3), 363-376; doi:10.1007/s10518-007-
9037-2.

Erdik, M., K. Sesetyan, M.B. Demircioglu, U. Hancilar and C. Zülfikar (2011). Rapid earthquake loss assessment after damaging earthquakes, Soil Dyn. Earthq. Eng., 31, 247-266; doi:10.1016/j.soildyn.20 10.03.009.

Faenza, L., and A. Michelini (2010). Regression analysis of MCS intensity and ground motion parameters in Italy and its application in ShakeMap, Geophys. J. Int., 180 (3), 1138-1152; doi:10.1111/j.1365-246X.2009. 04467.x.

Galli, P., R. Camassi, R. Azzaro, F. Bernardini, S. Castenetto, D. Molin, E. Peronace, A. Rossi, M. Vecchi and A. Tertulliani (2009). Il terremoto aquilano del 6 aprile 2009: rilievo macrosismico, effetti di superficie ed implicazioni sismotettoniche, Il Quaternario, 22, 235-246 (in Italian).

Garcia Moreno, D., and T. Camelbeeck (2013). Comparison of ground motions estimated from prediction equations and from observed damage during the $M=4.61983$ Liège earthquake (Belgium), Nat. Hazards Earth Sys. Sci., 13, 1983-1997; doi:10.5194/ nhess-13-1983-2013.

Gruppo di Lavoro MS (2008). Indirizzi e criteri per la microzonazione sismica - Conferenza delle Regioni e delle Province autonome - Dipartimento della protezione civile, Roma, 3 volumes and DVD (in Italian).

Gruppo di Lavoro MS-AQ (2010). Microzonazione sismica per la ricostruzione dell'area aquilana, Regione Abruzzo - Dipartimento della Protezione Civile, L'Aquila, 3 volumes and CD-ROM (in Italian); http:/ / www.protezionecivile.gov.it/jcms/it/micro zonazione_aquilano.wp.

INGV, Istituto Nazionale Geofisica e Vulcanologia (2009). ShakeMap, Event 2206496920; http:/ / shakemap.rm. ingv.it/shake/2206496920/products.html.

Ioannou, I., J. Douglas and T. Rossetto (2015). Assessing the impact of ground-motion variability and uncertainty on empirical fragility curves, Soil Dyn. Earthq. Eng., 69, 83-92; doi:10.1016/j.soildyn.2014.10.024.

ISTAT, Istituto nazionale di statistica (2001). Basi territoriali e variabili censuarie, http:/ / www.istat.it/it/ archivio/ 104317.

ISTAT, Istituto nazionale di statistica (2014). Descrizione dei dati geografici e delle variabili censuarie per sezione di censimento Anni 1991, 2001, 2011 (in Italian); avalaible at: http:/ /www.istat.it/it/files/ 2013/11/Descrizione_dati_20140310.pdf?title=Basi + territoriali $+\mathrm{e}+$ variabili + censuarie $+-+17 \% 2 \mathrm{Fmar}$ \%2F2014+-+Descrizione+dei+dati.pdf

Karakostas, C., V. Lekidis, A. Kappos, G. Panagopoulos, C. Kontoes and I. Keramitsoglou (2012). Evaluation of seismic vulnerability of buildings in Athens 
and L'Aquila in the framework of the MASSIVE seismic mitigation system, In: Proceedings of the 15th World Conference on Earthquake Engineering (Lisbon, Portugal).

Kaufmann, C., and J. Schwarz (2008). Modular system for seismic risk analysis considering uncertainties of basic input parameters, In: Proceedings of 14th World Conference on Earthquake Engineering (Beijing, China).

Kontoes, C., T. Herekakis, E. Ieronymidi, I. Keramitsoglou, A. Fokaefs, G.A. Papadopoulos, S. Paralikidis, D. Aifantopoulou, A.M. Deflorio, D. Iasillo and C.T. Kiranoudis (2012). Mapping seismic vulnerability and risk of cities: The MASSIVE project, J. Earth Sci. Eng., 2 (8), 496-513.

Lagomarsino, S., and S. Giovinazzi (2006). Macroseismic and mechanical models for the vulnerability and damage assessment of current buildings, B. Earthq. Eng., 4 (4), 415-443.

Lang, K., and H. Bachmann (2004). On the seismic vulnerability of existing buildings: A case of the city of Basel, Earthq. Spectra, 20, 43-66.

Liel, A.B., and K.P. Lynch (2009). Vulnerability of reinforced concrete frame buildings and their occupants in the 2009 L'Aquila, Italy earthquake, Quick Response Report, Natural Hazards Center of the University of Colorado, 213, $21 \mathrm{pp}$.

Locati, M., R. Camassi and M. Stucchi, eds. (2011). DBMI11, the 2011 version of the Italian Macroseismic Database, Milano-Bologna, http:/ / emidius.mi. ingv.it/DBMI11; doi:10.6092/INGV.IT-DBMI11.

Michelini, A., L. Faenza, V. Lauciani and L. Malagnini (2008). ShakeMap implementation in Italy, Seismol. Res. Lett., 79, 689-698; doi:10.1785/gssrl.79.5.689.

Mouroux, P., and B. Le Brun (2006). Presentation of RISK-UE project, B. Earthq. Eng., 4 (4), 323-339; doi:10.1007/s10518-006-9020-3.

Musson, R.M.W., G. Grünthal and M. Stucchi (2010). The comparison of macroseismic intensity scales, J. Seismol., 14 (2), 413-428; doi:10.1007/s10950-0099172-0.

Rivas-Medina, A., S. Martinez-Cuevas, L.E. Quiros, J.M. Gaspar-Escribano and A. Staller (2014). Models for reproducing the damage scenario of the Lorca earthquake, B. Earthq. Eng., 12 (5), 2075-2093; doi:10.10 07/s10518-014-9593-1.

Rossetto, T., N. Peiris, J. Alarcon, E. So, S. Sargeant, V. Sword-Daniels, C. Libberton, E. Verrucci, D. Del Re and M. Free (2009). The L'Aquila (Italy) Earthquake of 6th April 2009, A preliminary field report by EEFIT, 54 pp.

Sabetta, F. (2011). Abruzzo earthquake of April 2009: seismic sequence, ground motion attenuation, sim- ulation scenario and losses, B. Geofis. Teor. Appl., 52 (3), 427-442.

Sedan, O., M. Terrier, C. Negulescu, T. Winter, A. Roullé, J. Douglas, J. Rohmer, S. Bes-de-Berc, F. De Martin, C. Arnal, T. Dewez and M. Fontaine (2008). Scénario départemental de risque sismique - Méthodologie et processus de realisation, BRGM/RP-55415-FR. 459 pp., 96 figs., 45 tables, 25 ann. (in French); available at: http://infoterre.brgm.fr/search/switch.ht m?scope $=9$.

Sedan, O., C. Negulescu, M. Terrier, A. Roullé, T. Winter and D. Bertil (2013). Armagedom - A tool for seismic risk assessment illustrated with applications, J. Earthq. Eng., 17 (2), 253-281; doi:10.1080/136324 69.2012.726604.

Stucchi, M., R. Carnassi, A. Rovida, M. Locati, E. Ercolani, C. Meletti, P. Migliavacca, F. Bernardini and R. Azzaro (2007). DBMI04, il database delle osservazioni macrosismiche dei terremoti italiani utilizzate per la compilazione del catalogo parametrico CPTI04, Quaderni di Geofisica, 49 (in Italian).

Tertulliani, A., L. Arcoraci, M. Berardi, F. Bernardini, R. Camassi, C. Castellano, S. Del Mese, E. Ercolani, L. Graziani, I. Leschiutta, A. Rossi and M. Vecchi (2010). An application of EMS98 in a medium-sized city: The case of L'Aquila (Central Italy) after the April 6, 2009 Mw 6.3 earthquake, B. Earthq. Eng., 9 (1), 67-80; doi:10.1007/s10518-010-9188-4.

van Stiphout, T., S. Wiemer and W. Marzocchi (2010). Are short-term evacuations warranted? Case of the 2009 L’Aquila earthquake, Geophys. Res. Lett., 37; doi:10.1029/2009GL042352.

Wald, D.J., V. Quitoriano, T.H. Heaton and H. Kanamori (1999). Relationships between peak ground acceleration, peak ground velocity, and Modified Mercalli intensity in California, Earthq. Spectra, 15 (3), 557-564.

Zechar, J.D., M. Herrmann, T. van Stiphout and S. Wiemer (2014). Forecasting seismic risk as an earthquake sequence happens, In: M. Wyss and J.F. Shroder (eds.), Earthquake Hazard, Risk, and Disasters, Academic Press, 167-182.

Zuccaro, G., F. Cacace and D. De Gregorio (2012). Buildings inventory for seismic vulnerability assessment on the basis of census data at national and regional scale, In: Proceedings of the 15th World Conference on Earthquake Engineering (Lisboa, Portugal).

\section{Corresponding author: John Douglas,} BRGM - Bureau de Recherches Géologiques et Minières, Orléans, France; email: john-douglas@gmx.com.

C 2015 by the Istituto Nazionale di Geofisica e Vulcanologia. All rights reserved. 